Raising the standard: contradictions in the theory of student teacher learning

European Journal of Teacher Education

Alaster Scott Douglas

School of Education, University of Roehampton, London, UK

Email: alaster.douglas@ roehampton.ac.uk

Postal Address:

Room E002

Cedar Building

Froebel College

School of Education

University of Roehampton

Roehampton Lane

London SW15 5PJ

UK

ORCID iD: 0000-0003-0972-4315 


\section{Raising the standard: contradictions in the theory of student teacher learning}

This article offers a critical examination of the use of teachers' standards for student teachers in teacher education in England. Using an illustrative data example of student teachers working in a school department setting, benefits of a cultural historical activity theory analysis are forwarded. The example highlights shortcomings in the current education of student teachers which is in transition owing to changes in English teacher education policy. Focusing heavily on meeting required teachers' standards, the school teaching practice in the research example does not encourage student teachers or teachers to develop their understanding of teaching. Neither is the context of the teacher education work taken into account nor personal views of participants. Ways of analysing experiences recognising the influence of schools in affecting the kinds of learning available to student teachers are needed in England in order to increase understanding of the benefits and drawbacks of different approaches to school-based teacher education.

Keywords: teachers' standards; socio-cultural theory; student teachers; learning

\section{Introduction}

There is a central tension in teacher education in England where there is an oft noted mismatch in how government policy views learning to teach and how many researchers in the teacher education community view learning to teach (Marshall 2014). Government literature in England now refers to teacher training and teacher trainees as opposed to teacher education and student teachers and this has come about through the government's continued approach to teaching being a craft or an apprenticeship 'best learnt as an apprentice observing a master craftsman or woman' (DfE 2010b). Yet, research into learning opportunities for student teachers emphasises the importance of student teachers doing more than attempting to emulate the work of experienced teachers as advocated by such an apprenticeship model (Douglas 2014). Replicating the practices of teachers may be effective to a limited extent but learning in this way limits the novice teacher's understanding of what underpins the effective practices being observed and mastered. Simply focusing on the mastery of a set of techniques or meeting standards with criteria externally produced in public policy documents privileges process-product logic (Opfer and Pedder 2011) over personal understanding and 
development. The emphasis on reflection and reflective inquiry in many teacher education courses challenges this view of teachers as masters of a craft.

Those advancing a more technicist view have conceptualised learning to teach as a matter of simply acquiring competence 'on the job' (Furlong \& Smith 1996). This viewpoint is disputed from a range of perspectives, including those that privilege teachers' tacit knowledge (Hagger \& McIntyre 2006). Forms of distributed expertise found in the school context have also been increasingly identified as key to student teacher learning (Edwards $e t$ al. 2002). Benefits from school-based learning are seen to arise not only from increasing participation in teaching practices but in the critical examination of those practices by participants (Douglas 2011). However, examining difference and promoting debate and inquiry can be difficult when working in teacher education partnerships (Smagorinsky et al. 2003, 2004), even though 'in a truly effective collaborative relationship, dissimilarities between partners can in fact fuel the kind of intellectual discourse that interrupts traditional thinking and fosters the development of the teacher as knower' (Schulz \& Hall 2004, 267).

A participatory approach to pre-service teacher education leads to questions about why good teachers work in the way that they do. This does not view learning simply as a way of understanding 'what works', but recognises the need to understand why particular strategies work in specific classroom situations. In this school-based approach, one aim is to help student teachers understand the local setting and its practices. Therefore, experienced teachers help student teachers interpret and respond to events by sharing their expertise and local knowledge. Such a sociocultural pedagogy aims at assisting learners' participation in school communities where knowledge is used and constructed (Edwards et al. 2002), and therefore highlights the importance of school practice (or field experiences) in teacher preparation. Overly concentrating on prescribed teachers' standards limits the opportunities for student teachers to learn, as 'a standards-based technicized approach is unlikely to be responsive either to social contexts or to individual needs' (Menter 2009, 226).

A process of increasingly centralised control of initial teacher education in England has only partially been mirrored elsewhere in the UK and Europe. From the 1990s, teacher education policy in England and Wales became more school-focused while many European countries and other nations extended the process of placing teacher education under the auspices of 
universities. At a European level, the status of postgraduate courses had been bolstered by the Bologna agreement in 1999, which required all postgraduate qualifications in the European Union to be at Master's level. Master's level qualifications are important signifiers of the value of the research-based knowledge traditionally associated with higher education. This level of qualification in teacher education involves more time in the university and more sustained student teacher involvement in the development of research-literacy, the use of existing research to inform practice and active engagement in personal research (BERA 2014) with teaching seen as 'a problem to be solved' (Dickson 2011, 269).

The findings of a recent national review on teacher training in England (DfE 2015) reflect the contested place of universities in teacher education and forward a view of the dominant constructions of knowledge for teaching being practical and focused around the immediate demands of contemporary practice in schools. In England a fragmentation of the school system and of the numerous training routes into teaching may further weaken the conditions through which teacher knowledge is constituted. Changes in school governance for example, have meant that some schools are no longer required to employ teachers with qualified teacher status (Marshall 2014). To some extent this diminishes the centralised 'power over identifying the 'products' of teacher formation processes in England' (Hordern 2014, 232) and makes school leaders and school governors crucially placed to facilitate alternative experiences for new teachers learning how to teach. This significantly changes the landscape of teacher education.

In this paper, by using an example of data analysis from my own research in teacher education, I contextualise conceptions of student teacher learning by illustrating learning opportunities which are necessarily partial but which provide simplified descriptions of the kind of learning opportunities experienced by student teachers when working in schools in England. The intention is to consider the nature of school-based student teacher learning within a standards-based approach to teacher education and to identify cultural historical activity theory (CHAT) as an appropriate theory for analysing student teacher learning when teacher 'training' follows an advocated apprenticeship learning model.

\section{Cultural Historical Activity Theory (CHAT)}


The potential strength of a CHAT analysis in trying to address the question of how learning opportunities are available to student teachers in school is that it focuses attention on learning as a social phenomenon, a process that takes place within social systems that have evolved culturally and historically and that offer participants in those systems certain physical or psychological tools with which to work on a shared object. The significance of the learning tools available is seen in the way they are used (Engeström 2008). A tool can be both enabling and limiting; it may empower the tool user in "the transformation process with the historically collected experience and skill 'crystalized' to it, but it also restricts the interaction to be from the perspective of that particular tool' (Foot, 2014, 27). If discussions arising from tool use in teacher education, such as those around observation summaries, lesson plans and teacher standards are meaningful to student teachers' pedagogical experiences, these can affect their practices which may in turn feed back into how future discussions arising from the tools are shaped. Thus, opportunities for mutual and expansive learning can arise when tools are appropriated in this way, with the relationships of those using them open to learning. Expansive learning is possible when work is collaborative and new forms of practice are developed. However, tools may also be used restrictively. Consequences in relation to the restrictive use of tools have been analysed recently in a research study on home care work (Engström et al. 2015). Material tools in particular were seen to be effective in restrictive guarding of a standard script, thereby limiting activity to previously agreed upon procedures.

A central CHAT concept in this analysis is the idea of an activity's object. This is often described as the true motive of an activity (Leont'ev 1981). An object is always open to negotiation in an activity like teacher education where participants have different opinions and intentions with regards to the activity. Motives are revealed in how participants interpret and respond to the object. For example, some teachers may see teacher education as a way of developing new ways of teaching and learning in the classroom with a wish to extend their own pedagogical knowledge (possibly leading to expansive learning), whilst others may primarily want to 'give something back' to the profession by sharing their expertise (which is likely to be non-expansive). Therefore, interpretations of teacher education call forth responses to the objects of activity being worked on with the student teachers.

For a researcher, understanding how participants see the object of teacher education is possible by analysing how they work and use tools within the department's teacher education 
activity system. Tools are understood as anything that mediates participants' actions upon objects (Russell 2004). Physical tools (for example, lesson plans and lesson observation summaries) and non-physical tools (for example, discussions with student teacher mentors and debates with teachers on teaching and learning) develop within a specific culture and therefore create a link between historical and social processes and individual mental processes (Wertsch 2007, 178). Hence, their use says something about the department culture in which they have developed and may well give indications of how people see the purpose of the work. The tool itself does not necessarily determine how it is used. Consequently, the social practices inherent in using the tools become the focus of the research analysis with contradictions identified in the data opening up possibilities for negotiation and development. 'Studies of semiotic mediation have commonly excluded material tools' (Engeström 2016). CHAT emphasizes the material tool-mediated nature of communication and highlights the kinds of tools entailed in communicative actions such as particular forms of texts. The next section identifies one such text in teacher education in the form of the Teachers' Standards document (DfE 2013).

\section{Teachers' standards}

The Teachers' Standards (DfE 2013) are presented as the baseline standard for teaching in England and focus on thresholds for competence and conduct. The three parts of the document comprise a summary of teachers' values and behaviour, the Standards for Teaching and the Standards for Personal and Professional Conduct. The Standards for Teaching consist of eight main competence areas: setting high expectations, promoting pupils' progress and outcomes, demonstrating curriculum knowledge, planning lessons, adapting teaching to pupils' needs, using assessment, managing behaviour, and fulfilling professional responsibilities. Each standard is accompanied by bulleted subheadings (descriptors) in order to 'amplify the scope of each heading and these should be used by those assessing trainees and teachers to track progress against the standard' (DfE 2013, 7). Originally termed competencies, national teachers' standards in England are regularly revised in order to assess student teachers during their teaching course and school practices. Generic teaching standards have been adopted in many countries and have been criticised for being open to interpretation (Zeichner 2012) especially when their purposes are not fully understood. Research studies note that when meeting set standards is the main concern in learning to 
teach there is a danger of reducing the role of teachers to that of technicians who with narrowly defined competencies simply implement set strategies (Tatto 2006). Any process which becomes auditable in this way attracts temptations to 'game the system' (Bourdieu 1993 ) and fails to recognise the complex, contingent and human nature of teachers' practice. The contradiction that standards are open to interpretation but also narrowly defined has been seen to characterise contemporary discussions on professionalism: democratic professionalism which values social justice and equity and managerial professionalism which values efficiency, compliance and technical-rational responses:

There is a tension between the use of standards to support professional growth and bottom-up accountability, and their use as a top-down hierarchical and managerial means of ensuring compliance and performativity.

(Kennedy 2016, 147)

Professional standards are supported by trans-national bodies such as the European Commission (2013) and the $\operatorname{OECD}(2005,10)$ which states that countries should have 'profession-wide standards and a shared understanding of what counts as accomplished teaching'. The English 'Teachers' Standards' document (DfE 2013) is owned explicitly by the Government and presents official guidance published by the Secretary of State for Education. The managerial tone of the standards document is conveyed by the repetition of 'a teacher must' at the start of each standard description. Rather than using the standards as a means of discussing developmental aspects of the teacher's role, the standards 'need to be applied' (page 6) and the document is designed to help 'implement the standards effectively' (page 5). The performative aspect of the language is notable with references to assessing teachers' performance (mentioned seven times) and to 'new performance appraisal arrangements' (page 5). The document can also be used 'to assess cases of serious misconduct' (page 5), thereby highlighting its disciplinary function.

Focusing heavily on meeting required teachers' standards, in the same way as classroom teachers only teaching to the test, does not encourage student teachers to develop broader vision or take into account the context of their work and participants. Analysis of the recently revised national teachers' standards in England finds that they do not give sufficient attention to broader aspects of learning to teach such as gaining an understanding of 
educational theory or problematising educational values (Marshall 2014). Concern that some of the standards do not require students to be critically engaged in their practice or to consider disciplinary based knowledge suggests that meeting the teacher standards and learning the techniques necessary for performance are all that is necessary to realise teacher formation (Hordern 2014). Consequently, questions arise about where and how new teachers build their understanding of educational values and whether these now play a diminishing role in teacher formation.

The period from 1990 to the present day in England and developing across Europe has been characterised as a drastic loss of autonomy for teachers (Jeffrey 2011). Previously available professional collegiality from across education authorities in the shape of curriculum advisors and teacher groups has been replaced with school managerial team work. In many cases this work focuses on implementing government directed, centrally devised and controlled policies, practice and performance. The group dynamics of teachers working together has changed, and the added pressures of meeting targets and manager objectives impacts on work (Davies et al. 2009). The work of teachers now incorporates a performative professional role with the organisational structure of schools seen to 'discourage cultures of professional interaction and knowledge sharing' (Daniels 2006, 108). This is of particular concern at a time in England when greater responsibility and funding are being given to schools to prepare new teachers through, for example, the School Direct initiative (McNamara and Murray 2013). School Direct is a scheme set up to promote greater time for novice teachers to 'learn on the job' (DfE 2010a).

In this article I focus on the Teachers' Standards document as a tool used in the process of learning to teach and I report on research informed by cultural historical activity theory (CHAT) that investigated how the tool was appropriated in the activity of school-based teacher education.

\section{The research study}

The data from the research derive from a year-long ethnographic study exploring teacher education activities in four subject departments in one secondary school in the south of England. The research focused on a one-year teacher education programme at an established 
university and explored the learning opportunities for student teachers in their teaching practice. The Postgraduate Certificate of Education (PGCE) course has consistently been rated as outstanding by the government inspection arm: the Office for Standards in Education. The school in which the student teachers were placed was well regarded for the way its staff worked with the university with which it had been involved for over 15 years.

The fieldwork included participant observation of meetings between student teachers and their mentors (the cooperating or supervising teachers); meetings between university tutors, mentors and student teachers; lesson observations with feedback sessions from mentors; interviews with participants involved in teacher education activity (mentors, teachers, student teachers, university tutors and senior school managers); and numerous occasions observing social interaction in subject department 'team rooms'. The data-set comprises extensive field notes of lesson observations, mentor meetings and team room conversations. Field notes were handwritten in small notebooks, transcribed by myself and imported into qualitative data computer software. Guided by my own prior knowledge and experience of student teacher education and schools, and trying to make 'as few assumptions as possible' (Walford, 2009 , p. 274) I noted all details relevant to the focus of the research (learning opportunities for student teachers in teacher education activity in their practice school) and recorded key utterances verbatim, underlining them in my notes. I also analysed transcripts of recordings of formal meetings such as interviews and numerous documents.

For this article I look specifically at the use of the Teacher Standards Document (DfE 2013) in the science department because of the way the tool was appropriated in the teacher education activity. In the science department I observed 17 lessons and 19 mentor meetings. I interviewed the Head of Science and the 11 science teachers who worked with the student teachers. This included the student teachers' mentor who worked with two student teachers in the first school teaching practice beginning in the September of the research year and ending the following April, and three student teachers in the second (a shorter placement for 6 weeks in the summer term). Two university science tutors visited the school, one for each teaching practice. I do not here seek to understand everything the student teachers were learning. Therefore, the focus is exclusively on the mediation of the student teachers' learning by the Teachers' Standards document. 
Data were generated iteratively noting all aspects that seemed relevant to the learning opportunities of student teachers with the researcher's perspective deciding on data selection and reduction. Familiarisation was partly influenced by an interactive approach outlined by Huberman and Miles (1994). Initial coding reduced the data by creating categories, for example, department links with the university, the use of subject department team rooms and the use of the Teachers' Standards document. Qualitative data analysis software was used to label the transcribed field notes and interviews with categories that could then be extracted and arranged into bullet point lists in order to create synopses around initial codes. Interpretations of how the Teachers' Standards document was used were developed in analytic memos. Consequently, general procedures adopted for analysing data for the subject department analysis were by immersion in the data with the aim of generating areas for collation and comparison. As Huberman and Miles (1994) recognise, it was advantageous to continually move between reduction, display and drawing tentative conclusions in order to maintain a reflective stance.

The question that guided the research reported in this article asked whether and how the Teachers' Standards document (DfE 2013) mediates the learning of student teachers during their school teaching practice. I offer an analysis of how the document is used in the school to support student teachers' learning.

\section{Research findings}

In this section the data analysis considers the use of the Teachers' Standards document as a tool in teacher education activity. Where relevant in the data, I indicate in brackets the Teacher Standard and descriptor being referred to. Described by a teacher in another school department as 'a well-oiled machine' (teacher interview, 11 May) the science department worked closely together. The head of Science was proud of the detailed and organised schemes of work:

This is how we survive a busy year because everything is so well organised ... we have strong schemes of work, lessons seem to flow in a similar kind of way; we are quite frame-worked by necessity. (Interview, 16 January) 
The teachers in the science department expected the student teachers to be similarly 'frameworked' when working with the schemes of work. In their feedback they particularly concentrated on helping the student teachers gather evidence for meeting the teachers' standards. The standards were constantly referred to as needing to be evidenced in the student teachers' lessons and planning. The use of the standards terminology was prominent in lesson plans, discussion reports and on the observation summaries. 'Please make specific reference to the appropriate descriptor' is written in every section on the observation summary: i) the focus of observation, ii) achievements demonstrated during the lesson and iii) targets for future attention arising from the lesson. This encouraged a focus on the descriptors in post lesson discussions:

Mentor: But you need to be in control of where you are at, you need to prove with evidence, need it written down, your sheets and observation feedback sheets. You haven't always done that. Where do you keep the descriptors? At home? Under the bed? (laugh). This is the purpose of self-review sheets. So we need to decide now.

(He gets copies of the descriptors with tick box columns and they both fill them in).

Student teacher: So we are looking at the 'attention needed' column?

Mentor: Yes, do a quick review and tick where you think you are, and I'll do it too.

(They do this in silence for 2 minutes.)

Mentor: Anything with 'attention needed'?

(The mentor suggests appropriate targets and what the student teacher can ask staff to look for in observations.)

Mentor: Next week with your observation feedback and self-evaluation sheets we can see how you have done, OK? (Field notes, 16 January) 
Concern that the student teachers were not participating in a way that was expected, particularly in their taking responsibility for working towards meeting the descriptors made open discussion difficult, as the mentor felt that he needed to tackle these issues directly:

Mentor: You and [the other student teacher] don't seem to use planners - where are you setting goals for the pupils? [Standard 1 - Set high expectations which inspire, motivate and challenge pupils; set goals that stretch and challenge pupils]. You need to show progress and have this clear in the file: lesson plan with lesson evaluation and feedback. We need a system in place for writing data in your planners, so I am going to look at it next week ok? We need to shopping list the descriptors identified, so how are you going to make accurate use of assessment? [Standard 6 - Make accurate and productive use of assessment] (Field notes, 23 January)

An emphasis on ways needed to evidence meeting the requirements identified in the Teachers' Standards document dominated the mentor meetings. Using the Teachers' Standards document enabled a common ground to be established. This took the onus off the mentor, and allowed him to use the document as a mechanism for setting out the focus of tasks. In this respect, it often served to close down discussions with its emphasis on standards and codified learning points:

I found at times that I had to be quite forceful and say "no this is the case, you can't do that, you have to do this"” (Interview with science mentor, 27 June).

Therefore, the student teachers' practices were viewed in terms of the requirements set out. Tensions in ideas on teaching and learning were rarely brought to the surface, but instead there were tensions in the student teachers not meeting the expectations of the school department staff which were based on meeting the teachers' standards. The mentor discusses a student teacher's lesson preparation: 
Mentor: The majority of the class will find the lesson too difficult. I mind that you have spent so much time on this, but it won't work - put aside and move forward for tomorrow but keep the lesson. We can't tick off 'promote good progress' [Standard 2 - Promote good progress and outcomes by pupils; be aware of pupils' capabilities and plan teaching to build on these].

Mentor: My suggested activity provides for descriptors in explaining, instructions and classroom control. Let's put [on the lesson plan] ground rules and routines, secure attention of pupils and school procedures where necessary [Standard 7 Manage behaviour effectively to ensure a good and safe learning environment; have clear rules and routines for behaviour]. Put the descriptors on your observation summary and then bring your evaluation and feedback next week. (Field notes, 30 January)

The close monitoring of the standards' descriptors relaxed somewhat in the second teaching practice when the mentor was more confident with the student teachers' progress. It was also noticeably more relaxed at the end of the first practice when with the pressure off (as both student teachers had just passed their second assessment point), the nature of the discussion was freer with the student teachers contributing more openly. Meeting these descriptors therefore became the priority in lesson feedback when staff were not confident the student teachers were progressing. The practice of meeting the standards sometimes appeared to be prioritised before an understanding of why the standards needed to be met:

Mentor: Your subject knowledge is good and you are prepared, but one of your problems is with pitch - the source materials. You use the internet a lot but you should also look at revision guides and textbooks so as to get an idea about pupils' levels and what other people have taught. [Standard 3 - Demonstrate good subject and curriculum knowledge] (Field notes, 16 January)

Completing the student teacher education paperwork appeared to be the main focus of discussions in school mentor and university tutor meetings. Although advice is given above as to where to locate appropriately pitched resources (in revision guides and textbooks) the discussion did not consider the curriculum content at all. The teachers in the science 
department saw the teachers' standards document as a symbolic artifact of authority. The document guided the structure of what was to be talked about and helped to shape expectations of what the student teachers should be doing which affected how the student teachers perceived their learning. For example, the student teachers were encouraged to focus on aspects of teaching identified from the standards which were deemed by other staff as necessary of attention. One student teacher found this stressful and consequently avoided discussing teaching within the department:

I think that I would probably have benefited by talking to them (science staff) but I don't talk to them in general about teaching. I feel that it is an unnecessary stress for me, so I go to the staff room (Interview with student teacher, 21 February).

Despite the university handbook stating the importance of 'maintaining good records' for the student teachers' portfolio (page 51), both the university science tutors working with the school questioned the value of some of the teacher education paperwork. They wondered how much of an evidence gathering exercise it was purely to satisfy their, and the government's need for accountability:

As a useful document, it's useful for what? I think the portfolio was done as an assessment activity for us to monitor different aspects of the meeting of the standards. But is it a document that helps them learn? I couldn't hand on heart say that. (Interview with science tutor, 3 July)

The standards were not necessarily mediating student teacher learning. It was noticeable that checking forms dominated the university tutor visits: 'share that now so we can tick more boxes off' (tutor quotation from field notes, 21 November). This focus on accountability was particularly strong when visiting student teachers in preparation for their second school practice. The tutor noted development points for the next mentor:

Tutor: Let's carry on through your profile then

Mentor: Pace is a concern but getting better. When planning, consider the length of tasks and find the optimum length for each of the classes. It should be generally shorter to keep the pace up. I am concerned about that. What homework have you done with 
the year groups? You often just tick homework in planner to say done but you want more for reports and parents' evenings. Do you set extension work? For some tasks they were asking what to do next, so shall we make that a target?

Tutor: Ok, I'll make a note of that

(Field notes, 17 April)

The comments in the quotation above in relation to effective use of lesson time (pace), setting homework and extending pupils' knowledge and understanding are all references to the descriptors for meeting Teacher Standard 4 - Plan and teach well structured lessons (DfE 2013). By constantly trying to evidence that the student teachers were meeting the teachers' standards, the student teachers were always giving input from an 'unqualified' position, and as such they may have perceived their ideas as being unequal in comparison to the other participants. On the few occasions where considerations of the importance of professional values when conversing on matters of pedagogy were apparent (for example, when considering wider perspectives on how work in classrooms was viewed) this initiated discussions about the point of being there, and the value of education for both pupils and teachers. Nevertheless, many of the specific student teacher learning opportunities were couched in a rule-bound notion of complying with the course requirements and were used for gaining evidence of meeting the codified standards.

\section{A CHAT analysis of the data}

In CHAT terms, the school science department tended to appropriate the teachers' standards tool at a functional level within the work. This ensured that forms were completed and progress recorded. Like the use of the Teachers' Standards other tools appeared to replace possible discourse on specific contexts of teaching and the student teachers' interpretations of these (the mentor seeing observation feedback summaries as evidence of progress, for example). The department's desire to follow closely the expectations and required paperwork for the course meant that opportunities for debating lesson observation summaries and lesson plans in depth were limited. Consequently, a tendency for the student teachers not to work in the expected manner owing to their frustration at having to follow prescribed tasks based on meeting the teachers' standard descriptors ('I feel that it is an unnecessary stress for me' student teacher interview, 21 February) challenged the school department ('I thought I 
was wasting my time as you didn't want to know' mentor, 30 January). Instead of meetings leading to conversations about personal opinions on teaching and learning, they were used for establishing the teacher education activity system's rules ('you need to show that you are monitoring progress [standard 6] and have this clear in the file' - mentor, 30 January). The tools were used as a means to enforce the rules leaving little room for student teacher agency in the system.

Where there were few opportunities to affect the practice of the student teachers and their ways of thinking, one could view tools as secondary artifacts under Wartofsky's (1979) definition, simply acting as a representation of a primary tool in transmitting beliefs and norms, rather than colouring the way one sees the actual world in order to change current practice, which is the quality of a tertiary artifact. Considering a tool as a tertiary artifact could be possible with discussions in the school department opening out ideas that test thinking, and question aspects of pedagogy, and possibly lead to changing practice (expansive learning). As a secondary artifact, the teachers' standards information was imparted as a one-way process, and the complexity inherent in pedagogy was often hidden behind codified standards whose criteria were less contestable (non-expansive learning).

Helping student teachers to learn how to be novices in an established team appeared to be the main object motive for the teacher education activity in the science department. An established way of working within a tightly run department, meant that for the smooth running of the department, the expectations were that student teachers should be 'moulded' (interview with science teacher, $13 \mathrm{March}$ ). The social practices in the science department affected the student teachers' learning opportunities in that the student teachers kept their distance from the science team feeling that this eased the pressures for them in meeting department expectations. The university tutor in the first teaching practice sensed the mentor's bewilderment at the student teachers' lack of acquiescence and advised one of them to challenge less until they started to meet the department's expectations. As a consequence, the student teacher's thinking was rarely evident or explored as part of the teacher education activity:

Science mentor: I had a couple of staff come and say that they were concerned about how you [student teacher] were taking advice. I had that in mind when you didn't agree 
with my problem. I thought that other people were also feeling you were not taking advice. That is why I wanted to end the conversation on Friday. (Field notes, 30 January)

One aspect of the teacher education course ethos at the university was for student teachers to ask hard questions of the school working practices. But this was in tension with, and contradicted the student teachers being required to unquestioningly comply with the expectations of the teaching staff. Here there is a central contradiction in the activity system. The Teachers' Standards document is not being used as a tool for student teacher learning (by opening up thinking and problematising the teaching descriptors within the document) but the tool is acting as a rule in the teacher education activity system by being used instrumentally and without debate.

\section{Concluding thoughts: the value of contradictions}

School-based teacher education in England has meant that the onus and responsibilities of the school staff in the student teachers' learning have increased. Greater importance has been given to the school mentor's role with responsibilities for assessing the student teachers against the national standards. Working with contradiction in an open-ended process is particularly demanding within school settings. Such a questioning approach requires support and a culture that recognises and values debate and contestation as a way of working. As mentioned earlier, new demands on teaching tend to militate against a disruption of the management agenda, and consequently room for personal discussion around educational beliefs and values is marginalised.

Currently, the university teacher educator's role is changing, shifting from earlier notions of promoting teacher autonomy to supporting trainee teachers who are trained to comply with externally imposed teaching and assessment regimes (Brown et al. 2014). With the teacher educator's role moving into schools (White 2014) and university-based teacher educators being marginalised by new school-based training routes in England, new ways for encouraging learning opportunities are needed in schools if learning to teach is to involve forms of critical enquiry. If the recently revised teachers' standards in England approach the initial professional development of teachers in managerial terms, in so far as the standards 
mostly offer a list of pre-defined tasks and responsibilities (Marshall 2014) then learning is more likely to focus on what new teachers are expected to do, rather than adequately addressing what new teachers may think.

The system of teacher education in Finland, often favourably cited in teacher education literature does not focus on a system of national standards or teacher education national curricula (Sahlberg 2011). Influences from the Continental European policy of countries such as Finland and Portugal where all teacher education is at Master's level, and Norway and the Netherlands which have made significant policy moves in this direction have not impacted on current teacher education policy in England. Without building teacher education practices on knowledge informed by educational theory, it is even more important for student teachers to focus on the 'why' questions of education in order to be able to transform their learning to new situations and gain new insights. A focus on the quality of the learning experience for student teachers should be more than about observing set routines in order to replicate these in an apprenticeship model and then collating evidence of proof of performance. In educational contexts learning is more complex than transmission and transfer. In a school-based approach to student teacher learning, an experienced teacher's aim is to help student teachers understand the local situation and the effect this has on the teaching in the school (Edwards et al. 2002). Such a sociocultural pedagogy highlights that learning is about appreciating complexity and acknowledging the dilemmas and contradictions inherent in educational practice.

The CHAT analysis highlights how tools (in this paper the Teachers' Standards document) can be used in teacher education activity, and how they can function as rules in an activity system, thereby governing the participants' interactions:

This shift in the function of an artifact from tool to rule takes place typically when the artifact is perceived by the subject as an "administrative demand" designed and/or enforced by those with power over the subject to satisfy a requirement of one or more community members rather than as an instrument useful to the subject for engaging the object of the activity. (Foot 2014, 336) 
As suggested earlier, 'moulding' student teachers to be novices in an established team appeared to be the main object motive for the teacher education activity in the science department with the Teachers' Standards tool being seen as a symbolic artifact of the department's authority. As a practice-based and practice-oriented theoretical framework CHAT focuses on tool-mediated actions and can highlight consequences in relation to the expansive and restrictive use of tools. This contrasts with the foci of traditional Western social science that more typically features the attributes of individuals without reference to material things (Foot 2014). The CHAT framework is particularly pertinent to research on complex processes which are grounded in interaction and materiality. Contradictions arise from multiple participants' perspectives as collective practices evolve. Concentrating on student teacher education as a management activity to satisfy a government's need for accountability marginalises the focus on learning and most likely reduces possibilities for new learning.

There are also growing numbers of student teachers in England in work-based learning that are not taking part in university-led teacher education courses. Ways of analysing alternative experiences recognising the influence of schools in affecting the kinds of learning available to these student teachers are also needed in order to increase understanding of the benefits and drawbacks of new and different approaches to teacher education.

\section{References}

BERA (British Educational Research Association and the Royal Society of the Arts (RSA)). 2013. The Role of Research in Teacher Education: Reviewing the Evidence. http://content.yudu.com/Library/A2mkmg/BERAoneoffJanuary201/resources/index.htm?ref errerUrl=

Bourdieu, P. 1993. The Field of Cultural Production. New York: Columbia University Press.

Brown, T., H. Rowley, and K. Smith. 2014. "Rethinking research in teacher education." British Journal of Educational Studies 62 (3): 281-296.

Daniels, H. 2006. "Rethinking intervention: changing the cultures of schooling." Emotional and Behavioural Difficulties 11 (2): 105-120. 
Davies, P., S. Telhaj, D. Hutton, N. Adnett, and R. Coe. 2009. "Competition, cream skimming and department performance within secondary schools.” British Educational Research Journal 35 (1): 65-81.

DfE (Department for Education) 2010a. The Importance of Teaching. London: Department for Education.

DfE (Department for Education) 2010b. Michael Gove Speech to the National College Annual Conference. Birmingham. Available at: www.gov.uk (accessed 1 January 2015).

DfE (Department for Education) 2013. Teachers' Standards (rev. Jun). London: Department for Education.

DfE (Department for Education) 2015. Carter Review of Initial Teacher Training (ITT) London: Department for Education.

Dickson, B. 2011. "Beginning teachers as enquirers: M-level work in initial teacher education." European Journal of Teacher Education 34(3): 259-276.

Douglas, A.S. 2011. "The learning opportunities afforded student teachers in four secondary school subject departments in an initial teacher education school-university partnership.” Journal of Education for Teaching 37 (1): 93-106.

Douglas, A.S. 2014. Student Teachers in School Practice: An analysis of learning opportunities. London: Palgrave Macmillan.

Edwards, A., P. Gilroy, and D. Hartley. 2002. Rethinking Teacher Education: Collaborative Responses to Uncertainty. London: Routledge.

Engeström, Y. 2008. From Teams to Knots: Activity-theoretical studies of collaboration and learning at work. Cambridge: Cambridge University Press.

Engeström, Y., A. Kajamaa, and J. Nummijoki. 2015. "Double stimulation in everyday work: critical encounters between home care workers and their elderly clients." Learning, Culture and Social Interaction 4: 48-61.

Engeström, Y., J. Virkkunen, M. Helle, J. Pihlaja, and R.Poikela. 2016. "The change laboratory as a tool for transforming work." Center for Activity Theory and Developmental Work Research, University of Helsinki. Available at: http://citeseerx.ist.psu.edu/viewdoc/download?doi=10.1.1.691.8231\&rep=rep1\&type= pdf (accessed 25 May 2016)

European Commission, 2013. Supporting teacher competence development for better learning outcomes, European Commission Education and Training. Available at: 
http://ec.europa.eu/education/policy/school/doc/teachercomp_en.pdf (accessed 25 May 2016)

Foot, K.A. 2014. "Cultural-historical activity theory: exploring a theory to Inform practice and research.” Journal of Human Behavior in the Social Environment 24 (3): 329347.

Furlong, J., and R. Smith. 1996. The Role of Higher Education in Initial Teacher Training London: Kogan Page.

Hordern, J. 2014. "The logic and implications of school-based teacher formation.” British Journal of Educational Studies 62 (3): 231-248.

Huberman A., and M. Miles 1994. "Data management and analysis methods." In Handbook of Qualitative Research, edited by N. Denzin and Y. Lincoln, 428-444. Thousand Oaks, CA: Sage.

Jeffrey, R.A. 2011. "The development of the postmodern professional.” Paper presented at ECER, Berlin, September 13-16.

Leont'ev, A.N. 1981. "The problem of activity in psychology." In The Concept of Activity in Soviet Psychology, edited by J. V. Wertsch, 37-71. New York: Armonk NY.

Marshall, T. 2014. "New teachers need access to powerful educational knowledge.” British Journal of Educational Studies 62 (3): 265-279.

McNamara, O., and J. Murray. 2013. "The school direct programme and its implications for research-informed teacher education." In Learning to Teach Part 1. Available at: http://www.heacademy.ac.uk/assets/documents/disciplines/socialsciences/Strategic_2 014/LearningToTeach_Part1_Final.pdf

Menter, I. 2009. “Teachers for the Future: What have we got and what do we need?” In Changing Teacher Professionalism, International Trends, Challenges and Ways Forward, edited by S. Gewirtz, P. Mahony, I. Hextall and A. Cribb, 217-228. London: Routledge.

OECD, 2005, Teachers matter: Attracting, developing and retaining effective teachers, Paris: OECD

Opfer, V., and D. Pedder. 2011. "Conceptualizing teacher professional learning.” Review of Educational Research 81 (3): 376-407.

Sahlberg, P. 2011. Finnish lessons: what can the world learn from educational change in Finland? New York: Teachers College Press. 
Smagorinsky, P., L.S. Cook, and T. Johnson. 2003. 'The twisting path of concept development in learning to teach." Teachers College Record 105 (8): 1399-1436.

Smagorinsky, P., L.S. Cook, C. Moore, A. Jackson, and P. Fry. 2004. “Tensions in learning to teach: accommodation and the development of a teaching identity." Journal of Teacher Education 55 (1): 8-24.

Schulz, R., and C. Hall. 2004. "Difficulties in promoting inquiry in teacher education partnerships: English and Canadian perspectives." Journal of Education for Teaching 30 (3): 255-269.

Tatto, M. 2006. 'Education reform and the global regulation of teachers' education, development and work: a cross-cultural analysis." International Journal of Educational Research 45 (4-5): 231-241.

Walford, G. 2009. "For ethnography.” Ethnography and Education 4 (3): 271-282.

Wartofsky, M. 1979. Models, Representation, and the Scientific Understanding. Boston: Reidel.

Wertsch, J. 2007. “Mediation.” In The Cambridge Companion to Vygotsky, edited by H. Daniels, M. Cole and J. Wertsch, 178-192. Cambridge, UK: Cambridge University Press.

White, E. 2014. "Being a teacher and a teacher educator: developing a new identity?" Professional Development in Education 40 (3): 436-449.

Zeichner, K. 2012. “The turn once again toward practice-based teacher education.” Journal of Teacher Education 63 (5): 376-382. 